\title{
Growth of $\operatorname{InBi}_{x} \mathrm{Sb}_{(1-x)}$ films on $\mathrm{GaAs}\left(\begin{array}{lll}0 & 0 & 1\end{array}\right)$ substrates using liquid phase epitaxy and their characterization
}

\author{
V.K. Dixit ${ }^{\mathrm{a}}$, K.S. Keerthi ${ }^{\mathrm{a}}$, Parthasarathi Bera ${ }^{\mathrm{b}}$, H.L. Bhat ${ }^{\mathrm{a}, *}$ \\ ${ }^{a}$ Department of Physics, Indian Institute of Science, Bangalore 560012, India \\ ${ }^{\mathrm{b}}$ Solid State and Structural Chemistry Unit, Indian Institute of Science, Bangalore 560012, India
}

Received 7 February 2002; accepted 27 February 2002

Communicated by M. Schieber

\begin{abstract}
The growth of epitaxial $\mathrm{InBi}_{x} \mathrm{Sb}_{(1-x)}(x=4$ atomic \%) layers on highly lattice mis-matched semi-insulating GaAs substrates has been successfully achieved via the traditional liquid phase epitaxy, as a result of optimizing several growth parameters such as III/V mass ratio, growth temperature, cooling rate, etc. Scanning electron micrograph shows sharp interface even at $1 \mu \mathrm{m}$ resolution. The grown films are n-type in the entire temperature range. The typical value of the carrier density is $9.2 \times 10^{16} / \mathrm{cm}^{3}$ and the Hall mobility is $3.54 \times 10^{4} \mathrm{~cm}^{2} / \mathrm{V} \mathrm{s}$ at $300 \mathrm{~K}$. The room temperature band gap has been found to be in the range of $0.134-0.140 \mathrm{eV}$. These results indicate that the grown films are comparable to those grown by other sophisticated techniques in terms of structural, optical and electrical properties. (C) 2002 Elsevier Science B.V. All rights reserved.
\end{abstract}

PACS: 78.30.A; 81.05.E; 81.15.L

Keywords: A1. X-ray diffraction; A3. Liquid phase epitaxy; B1. Antimonides; B2. Semiconducting III-V material; B2. Semiconducting ternary compounds

\section{Introduction}

The room temperature (RT) infrared detectors operating in the $8-14 \mu \mathrm{m}$ wavelength range are very important in the fields of thermal imaging, pollution monitoring, space technology, etc. For such applications, although $\mathrm{Hg}_{x} \mathrm{Cd}_{(1-x)} \mathrm{Te}$ (MCT) has been the main material of choice in the past, it has proved to be a difficult compound to prepare due to high vapor pressure of $\mathrm{Hg}$ and the weak $\mathrm{Hg}$

\footnotetext{
*Corresponding author. Fax: +91-80-3602602.

E-mail address: hlbhat@physics.iisc.ernet.in (H.L. Bhat).
}

bond [1]. As an alternative, III-V based materials such as $\operatorname{InTl}_{x} \mathrm{Sb}_{(1-x)}, \operatorname{InAs}_{x} \mathrm{Sb}_{(1-x)}, \operatorname{InBi}_{x} \mathrm{Sb}_{(1-x)}$, etc, are being to be explored for these applications. Amongst them $\operatorname{InAs}_{x} \mathrm{Sb}_{(1-x)}$ and $\operatorname{InBi}_{x} \mathrm{Sb}_{(1-x)}$ have received much success in infrared (IR) detector applications [1,2]. In particular, $\operatorname{InBi}_{x} \mathrm{Sb}_{(1-x)}$ has the potential to replace MCT in future primarily due to its nontoxic property. However, it is very difficult to grow $\operatorname{InBi}_{x} \mathrm{Sb}_{(1-x)}$ crystals with higher concentration of $\mathrm{Bi}$ using equilibrium growth technique due to its low solid solubility limit $(2$ at $\%$ ) [3]. On the otherhand, there are successful reports on the growth of $\operatorname{InBi}_{x} \mathrm{Sb}_{(1-x)}$ on 
semi-insulating GaAs substrates (14.6\% lattice mismatch) using other growth techniques such as metal organic chemical vapor deposition (MOCVD) and molecular beam epitaxy (MBE) [4,5]. After successful growth of InSb on semiinsulating GaAs substrates using liquid phase epitaxy (LPE) [6,7], growth of $\operatorname{InBi}_{x} \mathrm{Sb}_{(1-x)} / \mathrm{GaAs}$ heterostructure was carried out using the same technique. In this paper we report LPE growth of $\mathrm{InBi}_{x} \mathrm{Sb}_{(1-x)} / \mathrm{GaAs}$ heterostructures and their structural, electrical and optical properties.

\section{Growth details}

$\mathrm{InBi}_{x} \mathrm{Sb}_{(1-x)}$ epilayers were grown in a boatslider type LPE unit designed and fabricated in our laboratory [8]. Growth was carried out on $\operatorname{InSb}\left(\begin{array}{lll}0 & 0 & 1\end{array}\right)$ and semi insulating chemically clean GaAs(l 001$)$ substrates of $10 \mathrm{~mm} \times 15 \mathrm{~mm}$ in area and $1 \mathrm{~mm}$ in thickness which were held in the recess of the slider that ran through the bottom of the indium-rich $\operatorname{InBi}_{x} \mathrm{Sb}_{(1-x)}$ solution bins. Indium-rich saturated solution was prepared with previously grown $\operatorname{InBi}_{x} \mathrm{Sb}_{(1-x)}$ crystals [9] and $\mathrm{In}+\mathrm{InSb}$ solution. The optimized $\mathrm{In} /(\mathrm{Sb}+\mathrm{Bi})$ mass ratio used for the growth was 1.86 . The solution temperature was increased $\approx 50^{\circ} \mathrm{C}$ above the growth temperature $\left(351^{\circ} \mathrm{C}\right)$ and baked for an optimum period of $6 \mathrm{~h}$ in ultra-pure hydrogen ambient for homogenization. In the present investigation we used ramp cooling routine because continuous decrease in temperature can provide a driving supersaturation $\beta \propto \Delta T / T_{\mathrm{g}}$ at every point during growth and induce orderly epitaxial growth [10] (where $\Delta T$ denotes the supercooling of the solution and $T_{\mathrm{g}}$ the initial growth temperature). The films were grown under varied conditions of supersaturation by changing the ramp rate $(R)$ and temperature range. It was observed that the lower growth temperature helped to incorporate more $\mathrm{Bi}$ with better homogeneity. The lower growth rate also improved the surface morphology of the epilayers. In a typical routine, the growth was initiated at $351^{\circ} \mathrm{C}$ by bringing the substrate under the solution and cooling it at the preset rate of $0.2^{\circ} \mathrm{C} / \mathrm{h}$. The cooling was stopped at the termination temperature of $349^{\circ} \mathrm{C}$ and the growth took place during this interval under controlled conditions. The substrate was then removed from under the melt by uniform slider pulling speed of $4 \mathrm{~cm} / \mathrm{h}$ which was achieved by an electro-mechanical system. Subsequently the furnace was cooled down continuously to $335^{\circ} \mathrm{C}$ with typical rate of $5^{\circ} \mathrm{C} / \mathrm{h}$ followed by $10^{\circ} \mathrm{C} / \mathrm{h}$ to $300^{\circ} \mathrm{C}$ and then furnace cooling was carried out down to room temperature.

\section{Structural characterization}

The growth rate $(r)$ was calculated by measuring the thickness of the film and the time of the growth. The thickness of the grown film varied from 2 to $15 \mu \mathrm{m}$ as calculated from Stylus and scanning electron micrography (SEM) experiments. Table 1 gives the correlation between imposed supersaturation $\Delta T\left({ }^{\circ} \mathrm{C}\right)$ and thickness of the film. The optimum growth rate was $0.2 \mu \mathrm{m} / \mathrm{h}$ which yielded $2 \mu \mathrm{m}$ film. The grown films were then leached in $\mathrm{HCl}$ to remove the carried over indium and chemomechanically polished with $0.06 \% \mathrm{Br}$-methanol solution. The cross section

Table 1

Diffraction intensity of $\mathrm{InBi}_{x} \mathrm{Sb}_{(1-x)} / \mathrm{GaAs}$ grown under various conditions.

\begin{tabular}{lllllllll}
\hline Run No. \# & $R\left({ }^{\circ}\right) \mathrm{C} / \mathrm{h}$ & $T_{\mathrm{g}}\left({ }^{\circ} \mathrm{C}\right)$ & $\Delta T\left({ }^{\circ} \mathrm{C}\right)$ & $r(\mu \mathrm{m} / \mathrm{h})$ & $(h k l)_{\max }$ & Other peaks & $I_{004} / \Sigma I_{h k l}$ & Thickness $(\mu \mathrm{m})$ \\
\hline 13C & 2.5 & 355 & 5 & 7.50 & $(004)$ & $(220)$ & 0.73 & 15 \\
20C & 1.5 & 353 & 3 & 5.00 & $(004)$ & $(220)$ & 0.89 & 10 \\
30C & 0.6 & 351 & 2 & 1.79 & $(004)$ & Nil & 1 & 6 \\
33C & 0.2 & 351 & 2 & 0.20 & $(004)$ & Nil & 1 & 2 \\
\hline
\end{tabular}




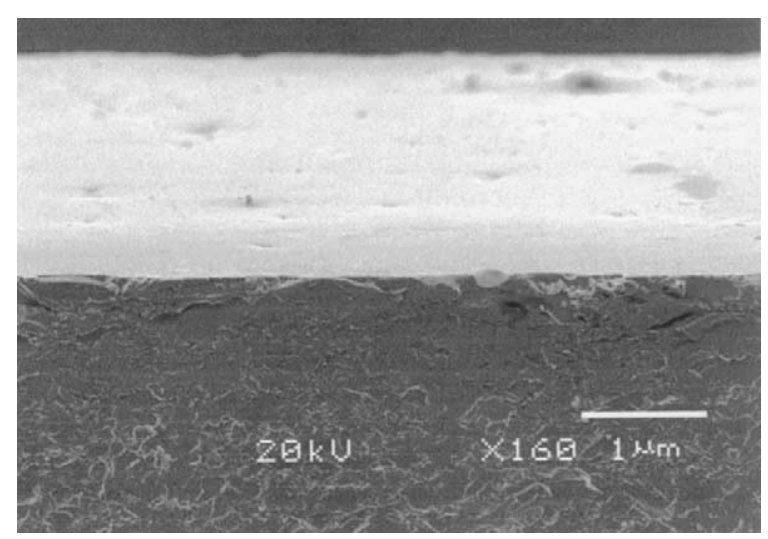

Fig. 1. Scanning electron micrograph of $\operatorname{InBi}_{x} \mathrm{Sb}_{(1-x)} / \mathrm{GaAs}$ interface.

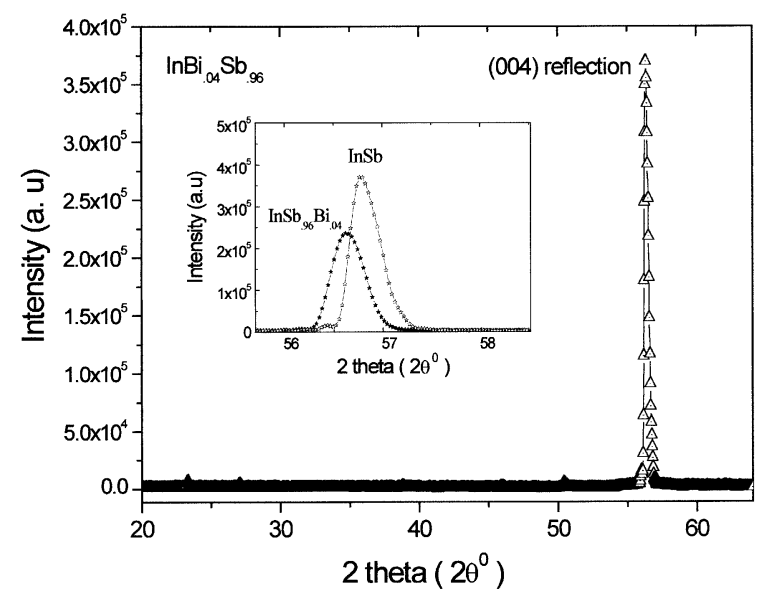

Fig. 2. X-ray diffraction pattern of $\operatorname{InBi}_{0.04} \mathrm{Sb}_{0.96}$ epilayer for $2 \theta$ scan from $20^{\circ}$ to $65^{\circ}$. Inset shows $(004) \mathrm{X}$-ray diffraction peaks of $\mathrm{InSb}$ and $\mathrm{InBi}_{0.04} \mathrm{Sb}_{0.96}$ epilayers.

of the cleaved sample as seen from SEM micrograph (Fig. 1), clearly reflects the sharpness of the interface between the $\operatorname{InBi}_{x} \mathrm{Sb}_{(1-x)}$ layer and $\mathrm{GaAs}$ substrate. During the SEM, simultaneous elemental identification was carried out with energy dispersive X-ray analysis (EDAX) to confirm that the region scanned was indeed film/substrate interface.

The composition $x$ of the grown films as found from EDAX was 2.18 at $\%$ with InSb substrates and 3.96 at $\%$ with GaAs substrates. It is to be noted that the incorporation of $\mathrm{Bi}$ is more when film was grown on GaAs substrate. This could be due to the influence of the residual strain energy (created due to the large lattice mismatch) on the miscibility gap. A single diffraction peak for $\mathrm{InBi}_{0.04} \mathrm{Sb}_{0.96} / \mathrm{GaAs}$ heterostructure confirms (00 1) orientation of the film (Fig. 2). The In$\mathrm{Bi}_{0.04} \mathrm{Sb}_{0.96}$ epilayer shows a clear shift of 004 peak towards a lower angle relative to $\mathrm{InSb}$ epilayer indicating lattice expansion due to substitution of $\mathrm{Bi}$ in $\mathrm{Sb}$ sites (inset in Fig. 2). The lattice constant of $\mathrm{InBi}_{0.04} \mathrm{Sb}_{0.96}$ calculated from X-ray diffraction data was $6.4798 \AA$ and matches well with that theoretically calculated $(6.4792 \AA)$ using Eq. [11]

$a=a_{\mathrm{InSb}}\left[1+\frac{\left(r_{\mathrm{Bi}}-r_{\mathrm{Sb}}\right)\left(C_{11}+2 C_{12}\right) x}{\left(r_{\mathrm{In}}+r_{\mathrm{Sb}}\right)\left(C_{11}\right) 2}\right]$,

where $a_{\mathrm{InSb}}$ is the lattice parameter of InSb and $\mathrm{r}_{i}$ are the Pauling values of the tetrahedral covalent radii of the respective elements, $C_{11}$ and $C_{12}$ are the stiffness coefficients of the InSb and $x$ is the concentration of bismuth.

Furthermore, X-ray photoelectron spectra (XPS) of $\operatorname{In}(3 \mathrm{~d}), \mathrm{Sb}(3 \mathrm{~d})$ and $\mathrm{Bi}(4 \mathrm{f})$ core levels on the $\operatorname{InBi}_{x} \mathrm{Sb}_{(1-x)}\left(\begin{array}{lll}0 & 0 & 1\end{array}\right)$ surface were recorded with ESCA-3 Mark II spectrometer using $\mathrm{AlK}_{\alpha}$ radiation $(1486.6 \mathrm{eV})$. The binding energies were measured with respect to $\mathrm{C}(1 \mathrm{~s})$ peak at $285 \mathrm{eV}$ with a precision of $\pm 0.1 \mathrm{eV}$. It has been found that surface of the as-prepared samples were slightly oxidized due to the exposure to atmosphere. Accordingly, peaks due to $\mathrm{InBi}_{0.04} \mathrm{Sb}_{0.96}$ phase as well as those due to $\mathrm{In}_{2} \mathrm{O}_{3}, \mathrm{Sb}_{2} \mathrm{O}_{5}$, and $\mathrm{Bi}_{2} \mathrm{O}_{3}$ were observed. Hence the surface was mildly etched with $\mathrm{Ar}^{+}$ion at low current $(20 \mu \mathrm{A}$ and $2 \mathrm{kV})$ for $5 \mathrm{~min}$, after which the sample was heated in vacuum of $10^{-9}$ Torr at $100^{\circ} \mathrm{C}$ for $2 \mathrm{~h}$. XPS of the heat-treated sample was then recorded. The observed XPS of core levels of $\operatorname{In}(3 \mathrm{~d}), \mathrm{Sb}(3 \mathrm{~d})$ and $\mathrm{Bi}(4 \mathrm{f})$ are shown in Fig. $3 \mathrm{a}-\mathrm{c}$, respectively. Spinorbit doublet peaks of $\operatorname{In}\left(3 \mathrm{~d}_{5 / 2,3 / 2}\right)$ are observed at 444.1 and $451.6 \mathrm{eV}$ which are slightly shifted to higher binding energy $(0.3 \mathrm{eV})$ as compared to In metal [12]. On the other hand, $\operatorname{Sb}\left(3 \mathrm{~d}_{5 / 2,3 / 2}\right)$ and $\operatorname{Bi}\left(4 \mathrm{f}_{7 / 2,5 / 2}\right)$ doublet peaks were observed at 527.8, $537.1,156.6$, and $161.3 \mathrm{eV}$ respectively, which are shifted to lower binding energy in comparison with respective metals [12]. In $\mathrm{Bi}$ spectrum other than 

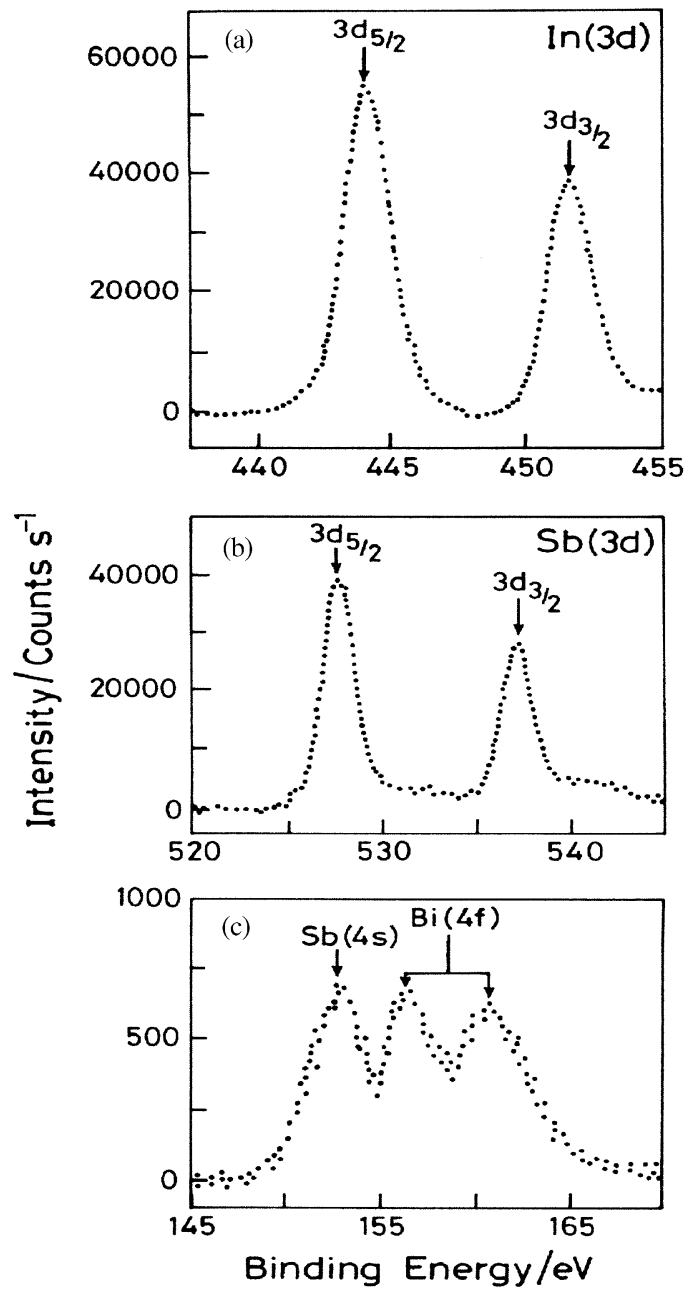

Fig. 3. X-ray photoelectron spectra of $\operatorname{InBi}_{0.04} \mathrm{Sb}_{0.96}$ for (a) In (b) $\mathrm{Sb}$ and (c) Bi.

$\operatorname{Bi}\left(4 f_{7 / 2,5 / 2}\right)$ doublet peaks, an extra peak was observed at $152.8 \mathrm{eV}$ which could be attributed to $\mathrm{Sb}(4 \mathrm{~s})$, because $\mathrm{Bi}(4 \mathrm{f})$ and $\mathrm{Sb}(4 \mathrm{~s})$ core levels are very close to each other. $\mathrm{Bi} / \mathrm{Sb}$ as well as $\mathrm{In} / \mathrm{Sb}$ ratios were calculated from the area under $\mathrm{Bi}(4 \mathrm{f})$, $\mathrm{Sb}(3 \mathrm{~d})$ and $\mathrm{In}(3 \mathrm{~d})$ peaks and were found to be 0.03 and 1.15 , respectively, which match reasonably well with the results obtained from EDAX. It was observed that with successive $\mathrm{Ar}^{+}$etching, the $\mathrm{Bi} /$ $\mathrm{Sb}$ and $\mathrm{In} / \mathrm{Sb}$ ratios remained the same, confirming that the composition of $\mathrm{Bi}, \mathrm{In}, \mathrm{Sb}$ in $\mathrm{InBi}_{x} \mathrm{Sb}_{(1-x)}$ does not change with thickness of the film.

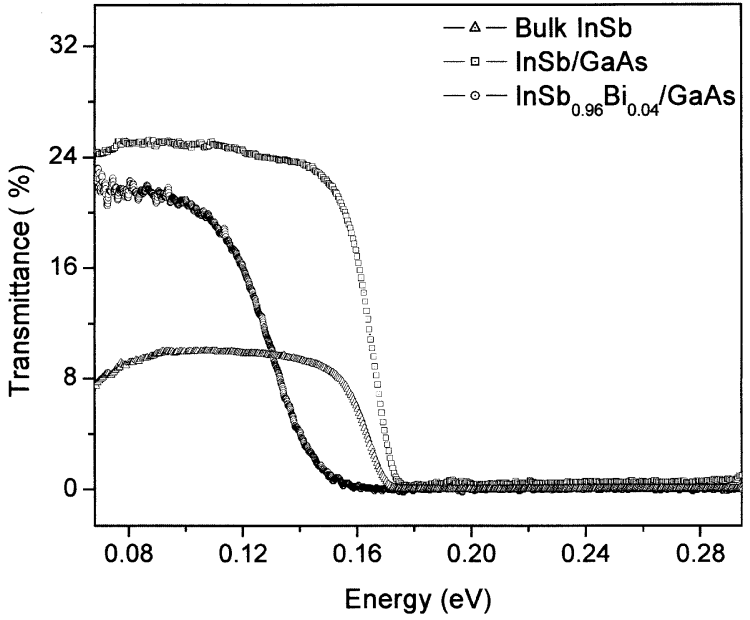

Fig. 4. At room temperature Infrared spectra of bulk InSb (for comparison), $\mathrm{InSb} / \mathrm{GaAs}$ and $\mathrm{InBi}_{0.04} \mathrm{Sb}_{0.96} / \mathrm{GaAs}$ room temperature.

\section{Optical and electrical characterization}

The infrared transmission spectra were recorded for the $\mathrm{InSb} / \mathrm{GaAs}, \mathrm{InBi}_{.04} \mathrm{Sb}_{0.96} / \mathrm{GaAs}$ epilayers as well as for bulk InSb wafer (for comparison) in the wavelength range $4-16 \mu \mathrm{m}$ using Jasco-32 spectrometer and are shown in Fig. 4. The room temperature band gap has been calculated for $\mathrm{InBi}_{0.04} \mathrm{Sb}_{0.96} / \mathrm{GaAs}$ samples using the relation [13] $\alpha=\alpha_{0}\left(h v-E_{\mathrm{g}}\right)^{n}$,

where $\alpha$ is absorption coefficient, $h v$ is the photon energy, $E_{\mathrm{g}}$ is the band gap and $n$ is a constant. The band gap was found to be in the range 0.134 $0.140 \mathrm{eV}$.

The carrier concentration was determined by Hall measurement using the conventional Van-der Pauw technique and the electrical resistivity was determined by the four point probe method. The samples were n-type in the entire temperature range. The maximum electron mobility was $3.54 \times 10^{4} \mathrm{~cm}^{2} / \mathrm{V} \mathrm{s}$ and carrier concentration was $9.2 \times 10^{16} / \mathrm{cm}^{3}$ at $300 \mathrm{~K}$. The temperature dependence of carrier density is shown in Fig. 5. As can be seen from the figure, the carrier density increases with temperature in the region 180 $370 \mathrm{~K}$, which implies that the intrinsic carriers are dominant in this region. On the other hand, in the 


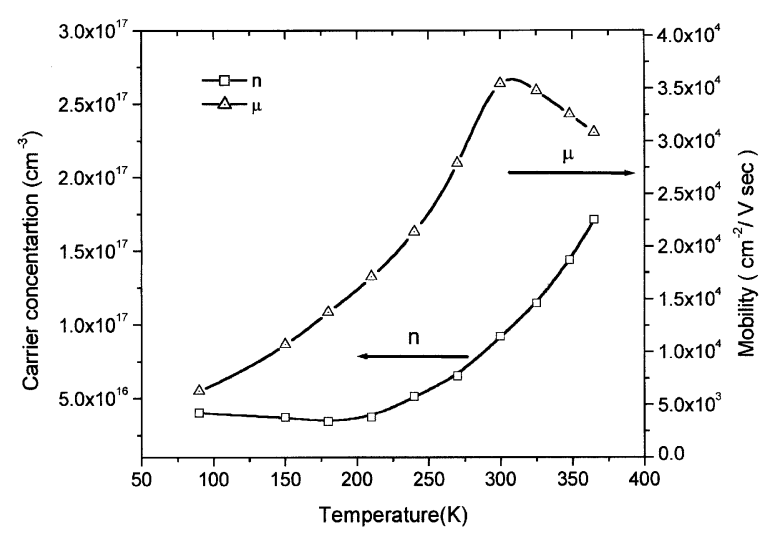

Fig. 5. Temperature dependence of carrier concentration and Hall mobility (film thickness $2 \mu \mathrm{m}$ ).

lower temperature region of $90-180 \mathrm{~K}$, the carrier density increases with decereasing temperature. This kind of anomalous behavior in carrier concentration has also been observed previously in thin layers and has been attributed to a two or three layer parallel conduction [14,15]. However, since the samples are relatively thick $(2-15 \mu \mathrm{m})$ such an interpretaion is not possible here. The possible causes could be due to Hall factor variation (which was assumed to be 1.00 in our calculation) or the nature and spatial distribution of dislocations along the growth direction. The temperature-dependent electron Hall mobility is also shown in the same figure. Below the room temperature the Hall electron mobility decreases with temperature, implying that the low temperature electron mobility of the sample is limited by dislocation scattering. Above room temperature, the mobility starts to drop, limited by a combination of electron, hole and phonon scattering [16].

\section{Conclusions}

In conclusion, growth of a highly lattice mismatched $\operatorname{InBi}_{x} \mathrm{Sb}_{(1-x)} / \mathrm{GaAs}$ heterostructure with 4 at $\%$ Bi concentration, has been achieved by the liquid phase epitaxy by optimizing several growth parameters. The layers grown under optimum conditions yielded good interface morphology as seen from SEM figures. Lattice parameter of $\mathrm{InBi}_{0.04} \mathrm{Sb}_{0.96}$ as determined from $\mathrm{X}$-ray diffraction pattern is $6.4798 \AA$ and matches with the theoretically calculated $(6.4792 \AA)$ value. The grown films are of n-type in the entire temperature range of measurement. The typical value of electron mobility and carrier concentration are $3.54 \times 10^{4} \mathrm{~cm}^{2} / \mathrm{V} \mathrm{s}$ and $9.2 \times 10^{16} / \mathrm{cm}^{3}$, respectively, at $300 \mathrm{~K}$. The room temperature band gap is found to be in the range $0.134-0.140 \mathrm{eV}$. Results indicate that the grown films are as good as the films grown by MOCVD and MBE in term of structural, optical and electrical properties.

\section{Acknowledgements}

This work is partially supported by a DTSR project which is gratefully acknowledged. We thank Prof. M.S. Hegde, Solid State and Structural Chemistry Unit, IISc., Bangalore, for allowing us to carry out the ESCA experiments and for useful discussion. One of the authors (VKD) acknowledges CSIR, India, for the award of a senior research fellowship.

\section{References}

[1] J.J. Lee, J.D. Kim, M. Razeghi, Appl. Phys. Lett. 73 (1998) 602.

[2] J.D. Kim, S. Kim, D. Wu, J. Wojkowski, J. Xu, J. Piotrowski, E. Bigan, M. Razeghi, Appl. Phys. Lett. 67 (1995) 2645.

[3] B. Joukoff, A.M. Jean-Louis, J. Crystal Growth 12 (1972) 169.

[4] J.J. Lee, J.D. Kim, M. Razeghi, Appl. Phys. Lett. 70 (1997) 3266.

[5] A.J. Noreika, W.J. Takai, M.H. Francombe, C.E.C. Wood, J. Appl. Phys. 53 (1982) 4932.

[6] V.K. Dixit, B.V. Rodrigues, R. Venkataraghavan, K.S. Chandrasekharan, B.M. Arora, H.L. Bhat, J. Crystal Growth 235 (2002) 154.

[7] V.K. Dixit, B. Bansal, V. Venkataraman, G.N. Subbanna, K.S. Chandrasekharan, B.M. Arora, H.L. Bhat, Appl. Phys. Lett. 80 (2002) 2102.

[8] R. Venkataraghavan, N.K. Udayashankar, B.V. Rodrigues, K.S.R.K. Rao, H.L. Bhat, Bull. Mater Sci. 22 (1999) 133.

[9] V.K. Dixit, B.V. Rodrigues, H.L. Bhat, J. Crystal Growth 217 (2000) 40.

[10] M. Elwenspoek, J. Crystal Growth 76 (1986) 514. 
[11] N. Chen, Y. Wang, H. He, L. Lin, Phys. Rev. B 54 (1996) 8516.

[12] D. Briggs, M.P. Seah, Practical Surface Analysis by Auger and X-ray Photoelectron Spectroscopy, Appendix 4, Wiley, New York, 1984.

[13] O. Madelung, Semiconductors-Basic Data, Springer, Berlin, 1996.
[14] J. Heremans, D.L. Partin, D.T. Morelli, C.M. Thrush, G. Karczewski, J.K. Furdyma, J. Appl. Phys. 74 (1993) 1797.

[15] E. Michel, H. Mohseni, J.D. Kim, J. Wojkowski, J. Sandven, J. Xu, M. Razeghi, R. Bredthauer, P. Vu, W. Mitchel, M. Ahoujja, Appl. Phys. Lett. 71 (1997) 1071.

[16] V.W.L. Chin, R.J. Egan, T.L. Tansley, J. Appl. Phys. 69 (1991) 3571. 